Fyhn, Håkon and Andersen, Lars (2019). "Team-leader Walk as Interdisciplinary Communication Tool at the Building Site." In: Proc. 27th Annual Conference of the International. Group for Lean Construction (IGLC), Pasquire C. and Hamzeh F.R. (ed.), Dublin, Ireland, pp. 1251-1262. DOI: https://doi.org/10.24928/2019/0206. Available at: 〈www.iglc.net>.

\title{
TEAM-LEADER WALK AS INTERDICIPLINARY COMUNICATION TOOL AT THE BUILDING SITE
}

\author{
Håkon Fyhn' ${ }^{1}$ and Lars Andersen²
}

\begin{abstract}
This paper introduces the concept of 'team-leader walk' as part of the construction process organized through TAKT production. The purpose of the team-leader walk, is to help teamleaders see, communicate and plan further ahead in the construction process. By systematically walking through the different zones of the building under construction, while discussing plans and coordination issues one to three weeks ahead, the building site is used as communication tool in the interdisciplinary communication between the teamleaders. Appealing to the often-well-developed practical intelligence of the team-leaders, we argue that the building site itself, enhances the ability to look ahead better than visualisation tools alone. The team-leaders, as last planners become better equipped to take part in the continuous planning. A condition for the team-leader walk, as presented here, is that the construction is organised according to a systematic movement in time and space such as TAKT production.

The study is based on observations and interviews at two building projects where the team-leader walk was tested in 2018 . While the validity is limited by the number of cases, the building company in study find the results so promising they have decided to implement the team-leader walk in further building projects.
\end{abstract}

\section{KEYWORDS}

Lean construction, team-leader walk, last planner, takt.

\section{INTRODUCTION}

A core idea in the last planner system is to engage those who actually do the job in the planning of it (Ballard 2000). This implies involving builders and team-leaders in the planning process. In particular the team leaders play an essential role in planning and coordinating the activities at the production front of the building site. In the present case study of two building projects lead by the same entrepreneur, the team-leaders engage in planning activities organised in a system similar to the last planner system, called Involved Planning (IP).

Senior Researcher, NTNU Social Research, Trondheim Norway, hakon.fyhn@ntnu.no

2 Research Professor, NTNU Social Research, Trondheim Norway 
Table 1: The time horizons of different meetings in IP (from Andersen 2016)

\begin{tabular}{|l|l|}
\hline Type of meeting: & Time horizon: \\
\hline Team meeting & 1 week \\
\hline Team-leader meeting & $1-3$ weeks \\
\hline Operations meeting & $4-8$ weeks \\
\hline Construction meeting & More than 8 weeks \\
\hline
\end{tabular}

In this system, the team-leaders meet every week. The team-leader meeting's contribution to planning implies looking ahead, from only one to three weeks. However, experiences from previous projects indicate that looking three weeks ahead is difficult as there is a tendency that the planning ahead is overshadowed by here and now concerns (Andersen 2016). The three-week perspective is made a topic at the meeting, but the experience is that it has been difficult to engage the team-leaders to come up with issues in great enough detail that concern the three-week time-frame. The poorer the process control, the shorter the time horizon (Andersen 2016). The result has been that issues which should have been sorted out three weeks before production, are discovered too late, creating problems for the construction proses.

In response to this situation, the team-leader walk, or just 'walk' (in Norwegian 'Basrunde') is introduced in order to help the team-leader meeting to see and plan three weeks ahead. One aspect separating this approach to the team-leader walk from similar planning practises is its explicit relation to the TAKT organisation of the building process. With TAKT the production front and horizon three weeks ahead is structured in a specific way in terms of systematic movement in time and space through the building, divided in zones.

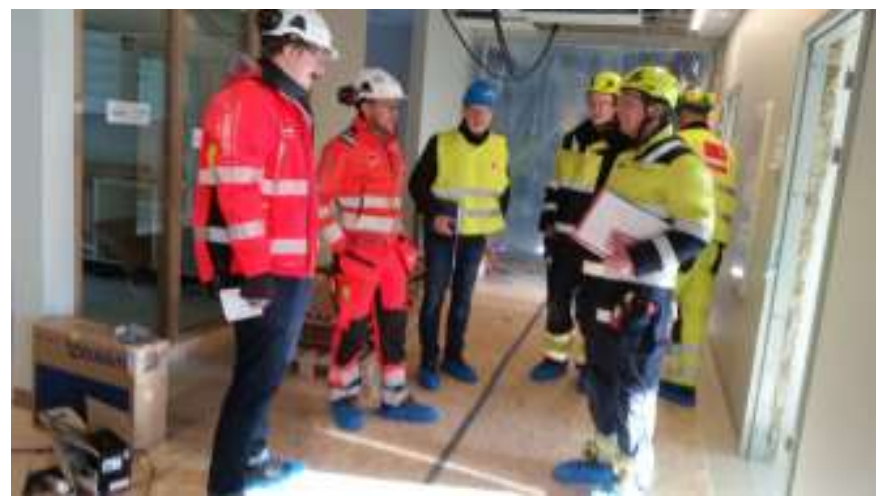

From team-leader walk case 1 .

\section{METHOD}

This paper is based on action research where the authors in collaboration with the entrepreneur have suggested and implemented the team-leader walk as an innovation to the established building processes. The walk is implemented and studied in two case studies in Norway: The first is a mid-sized hospital building, the second a sport stadium. The idea of the team-leader walk is based on previous studies at the same building company by the authors (Andersen 2016; Fyhn and Søraa 2018) which indicate the need for an implementation enhancing the ability to see three weeks ahead. The walk is adapted to the 
specific production system and production philosophy at the entrepreneur in study; a combination of TAKT production and "Involved Panning" (quite similar to Last Planner).

The implementation of the walk is made in close collaboration with the company management, the construction, and operations managers, and the team-leaders. The implementation is studied by participatory observations where the authors joined the teamleader walks as well as team-leader meetings, taking notes to what was said and done, which topics came up and how they were solved/not solved. In addition, semi-structured interviews were conducted with team-leaders, builders, engineers and management. The interviews focused on experiences with the walk as well as with the building process in general, and with suggestions for improvements.

The first case study was conducted from January to April 2018, involving observation of three team-leader walks and team-leader meetings. Interviews with team-leaders for carpenters, electricians and locksmiths was conducted in association with the observations. Follow up interviews was conducted with operation manger and construction manager. All interviews were semi-structured and qualitative.

For the second case, the implementation was studied from April to November 2018, including observations of six team-leader walks and the corresponding team-leader meetings. In addition, six semi structured qualitative interviews were conducted at the end of the period: with the team-leader for carpenters; team leaders for electricians, ventilation and plumbing; two carpenters; the foreman; operation manager; construction manager. For both cases, workshops with the responsible partners where held at the start of the observation period, mid-way and after the observations. This to ensure proper dialogue between researchers and industry partner in the development of the team-leader walk, research and implementation method, as well as to ensure relevance of the results. The workshop in the start was used to introduce the concept of team leader walk, as well as to find solutions for practical application in collaboration with the team leaders and management. The mid-way workshop was held to adjust the course of the experiment, and gather responses so far. The last workshop was held after the observation period when we hade systematised the finding. The purpose was to present results from the observations and to discuss them with the involved team-leaders and management.

\section{THE TEAM-LEADER WALK EXPLAINED}

Within a Lean mind-set, the team-leader walk draws on the Japanese concept 'Gemba walk', a tool in Lean leadership (Womack 2011) with parallels to the less structured western concept 'management by walking around'. In contrast to the Gemba walk, the team-leader walk is not about management leaving their office to walk the shop-floors, but rather about the team-leaders which already work at the 'floor' of the construction-site, walking around this site in a systematic manner when planning ahead. The idea is not primarily to allow team-leaders to experience the 'construction floor' but rather allow the actual construction site to enhance the interdisciplinary communication between the teamleaders, helping them to see further ahead in their interdisciplinary construction process. As such, it is the respect for the actual place - the 'Gensi genbutsu'- which resonates the most with established Lean leadership principles. 
Using the actual place, the building site, to enhance the interdisciplinary communication between team-leaders makes the building site into a boundary object; an object shared by participants of interdisciplinary communication allowing for common meeting ground despite differences (Boland and Tenkasi 1995). As a mediating object, the building under construction should be understood as a similar tool along with technical drawings, BIM models and time schedules on the wall; objects expressing the intended building or state of the art in various levels of detail. These are objects used by builders and team-leaders when communicating, planning and coordinating the work process. They are not only used to communicate ideas, plans and concerns, but also serve as mediums for developing ideas, plans and solutions, for example when the team-leader draw new lines on the technical drawing in order to show adjustments or new details. A more precise term than boundary object, may be 'communication tool'. Understood as communication tool the building under construction has certain properties which differs from drawings and BIM models. It is at any time the most updated version of the building progress. It also seems to appeal to practical thinking over the more theoretical associated with representational models, thus it may fit better into the cognitive expertise of many builders.

The team-leader walk is developed in a context of TAKT, where the flow of production is managed through the systematic movement of teams of builders through zones of the building. TAKT was the organising principle for the construction process in both cases studied in this paper. The buildings where divided into a number of zones estimated to imply close to similar amounts of work for the teams of builders.

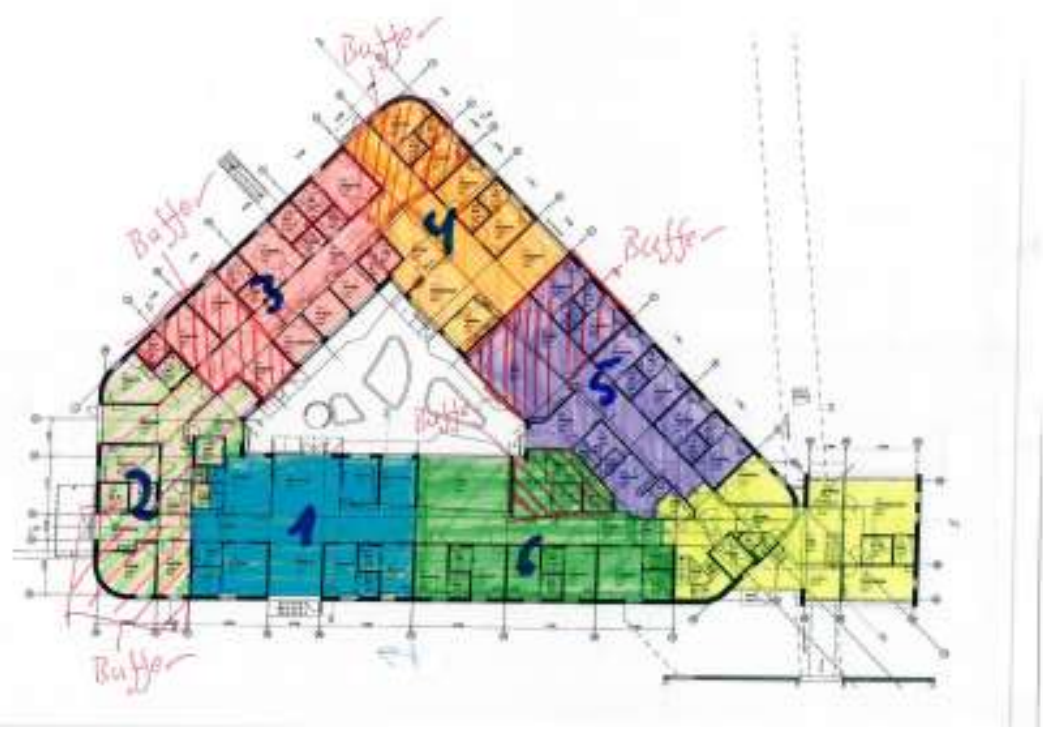

The TAKT plan for case 1, where the building is divided into zones 1-6. Yellow area is built outside TAKT and the hatched areas are buffer zones.

In both cases, the zones were defined as one week of work. Thus, the teams of builders, called wagons, moved though the building, one after the other like a train using one week in each zone: Typically starting which carpenters, followed by plumbers, electricians, more carpenters, etc. The important point which allows for the team-leader walk, is that the 
building is divided into specific zones which each team/wagon will move through according to a defined route. The idea it that when working within the TAKT production, the systematic movement through the different zones, movement in space becomes like movement in time, allowing the situation coming up three weeks ahead to manifest 'here and now', as they walk into that particular zone. Thus, the walk uses a possibility produced by the particular structure of the production front is given in TAKT organisation.

As the team-leaders walk through the building, they follow the same route as when constructing. Thus, if a team leader starts the walk in the zone he or she is presently working in, the team-leader will first walk into the next zone where he or she shall work next week, after that, the team-leader will walk into the zone he or she will be working in two weeks ahead, the final zone to walk through is the one laying three weeks ahead. As the group of team-leaders walk together, they are given opportunity to discuss plans and problems that will arise in one, two and three weeks ahead.

As the team leaders normally work in different wagons, following each other, the zone where one team, e.g. carpenters, works one week, will be the zone the next team, e.g. electricians, will work the week after. By walking together though this particular zone, they are given opportunity to discuss how the next team would prefer various details to be preserved when taking over the zone from the previous team; for example, the electrician requests from the carpenter in the wagon ahead that he would like to have a certain amount of space in a certain wall to ease his work with cabling. At the team-leader walk, it is possible to discuss this before the carpenters start putting up that particular wall.

In order to structure the discussions at the walk, the professions representing the wagons of week 1, 2 and 3 would take turns presenting status, particular needs and concerns in the interdisciplinary junctions with the other wagons. Also, they would discuss particular concerns and uncertainties regarding deliveries, solutions. A dedicated form vas developed in order to accommodate the note-taking during the walk, the form was printed as a notebook:

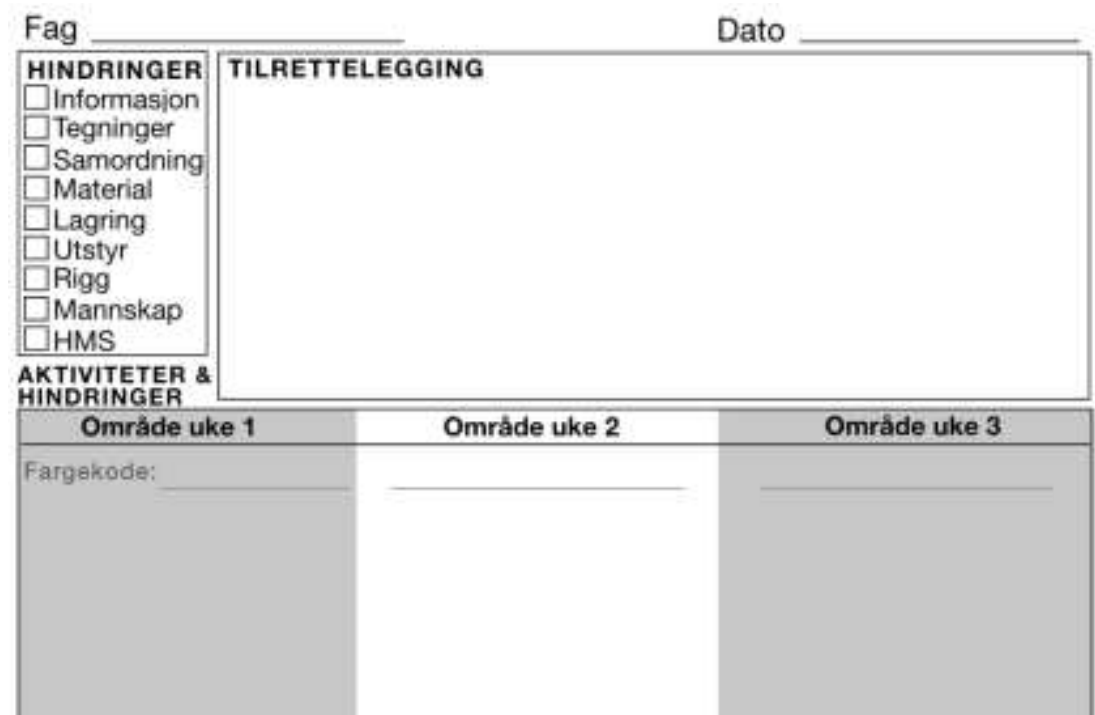

The form (designed by Marie Nilsen). The first field on top right is for 'obstacles' (information, drawings, coordination, materials, storing, equipment, rig, staffing, safety). 
The second field on top is for 'measures taken'. Below is three fields for notes, pointing 1, 2 and 3 weeks ahead. Each field has a place on top to note the colour of the specific control area in question (the control areas are distinguished by different colours).

Ideally, the team leader walk should not take up more time than 30-45 minutes. Issues brought up during the walk should be brought to the following team-leader meeting (using the above form), where also the foreman and operation manager is present, making this meeting more able to actually solve issues laying two-three weeks ahead.

\section{EXPERIENCES WITH THE TEAM-LEADER WALK}

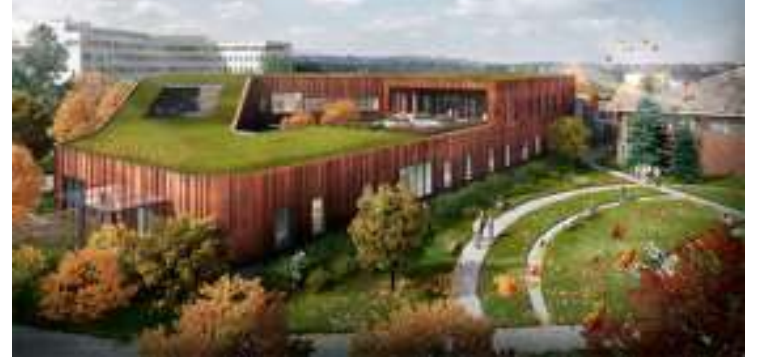

The first experiment with the team-leader walk was with case one, a hospital building specialised for psychiatric patients. The building is approximately $27000 \mathrm{~m}^{2}$, with a budget of $€ 19$ million. The construction process was organised according to principles of Lean construction and Last planner, using VDC. The building was organised in control zones where production was organised according to TAKT. The wagons of the construction train consisted of 1) carpenters, 2) technical, 3) carpenters, 4) painters, 5) ventilation, 6) carpenters, 7) technical, 8) carpenters. The building started in 2017 and was already running as the researchers came in. The implementation of the team-leader walk happened at time when walls and roof was up, but the interior work remained. Thus, the professions being most active in these team-leader walks was carpenters and technical installers (electro and locksmiths). The main focus was on the collaboration between these three team-leaders.

In this project, the TAKT organisation run into trouble due to delays in plans from the design team, and in the deliveries of certain producers, causing the drawings of certain walls and technical systems to be incomplete at the time the first wagons of the TAKT train arrived at the control zone. For example, the solutions to the roofs of certain hallways and the exact location of certain plumbs were not decided, also the builders had to wait several months for the right kinds of doors to arrive. Having to leave these elements for later when moving ahead according to the TAKT plan, the train soon lost its logistic rail and an increasing number of builders started to move back and forth in the building in order to fix things they had have to leave for later. Eventually the whole TAKT system was given up, causing also the team-leader walk to be given up. As such, the experiment had to be determined prematurely. Observations and interviews with the involved team-leaders, however, still indicated that this approach had helped them see ahead in the building 
process, even though their vision had been blurred by the lack of stringent movement in time and space. In particular we observed how the team-leaders managed to detect certain details such as the positioning of wholes for wires for electric door locks, by discussing the issue while standing by the doors in question. This way the locksmith was able to plan two weeks ahead, saving time and work, by making sure the carpenters enhanced optimal positioning for the wires the very first time. But in this particular project the future proved to be quite unpredictable. We should note that the builders managed to finish the project relatively on time, despite the loss of TAKT.

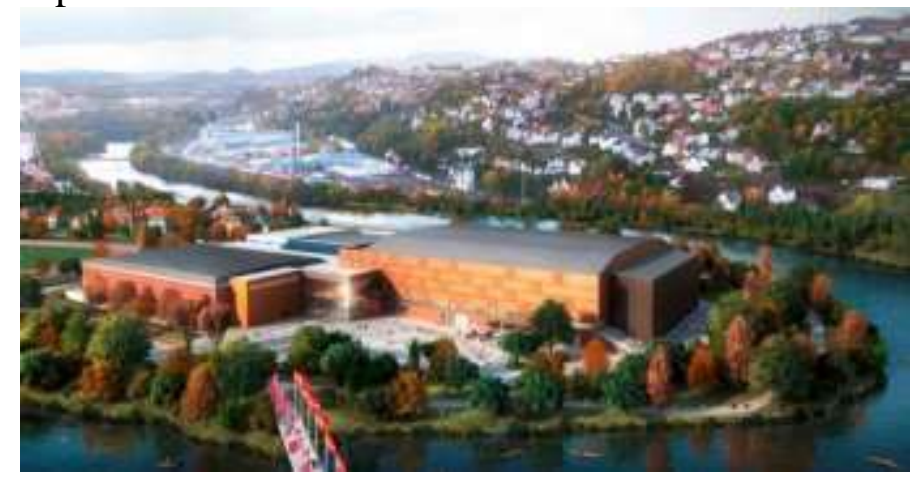

The second case is an indoor sports arena, which also is intended used as concert hall, housing 12000 people. Part of the arena is an office building, which is a redesigned and extended part of an already existing building. The office building is constructed using TAKT production. The budget is approximately $€ 4,5$ million, implying a TAKT team of 15 builders from various professions.

In this case, the team-leader walk was introduced earlier in the project compared to case one. The walk was conducted Fridays, while the team-leader meeting was held the following Monday, with the operations- and construction meeting the following days. Following the team-leaders at six walks though out the constriction process. The walk gathered team-leaders from carpenters, painters, plumbing and ventilation. Again, the walk proved fruitful as a medium for team-leaders to recognise and discuss coordination of details the different professions were interdependent of.

As in case one, the TAKT production encountered problems also in case two. Particularly the carpenters had increasing problems keeping up the planned pace of production, keeping the train on track. There were many reasons for these problems: One being an initial understaffing of carpenters when laying the TAKT plan. Another was delayed decisions from the project owner, causing essential aspects of the building (such as the façade solutions) to be unsettled long after the TAKT train had started. Also the ground work outside the building had been given priority, causing problems for the righton-time deliveries as the most useful accesses to the building site was closed in periods. Finally there where exhibition arrangements in parts of the building during production, interrupting the logistic of production. In sum, these interruptions caused severe problems for the TAKT production. After a couple of months, the TAKT production was given up. At this point, in June 2918, the team-leader walk was well established. Despite giving up TAKT the team-leaders decided to go on with the team-leader walk (the decision was made without input from the researchers). In contrast to case one, it was here possible to keep up 
the walk as the production was still space-based (Kenely and Seppänen 2009) and moved systematically though defined zones, though not according to the strict procedures and timing of TAKT.

During the walks the team leader for carpenters tended to take lead and initiated most activities. This is natural as the carpenters represented the constructing company and played a role in providing for the other disciplines. The carpenter team leader used his own note book in addition to the dedicated forms. Team leaders from the other disciplines did not take notes regularly. The team leaders tended not to use drawings or BIM during the walk (with a few exceptions). This was used more regularly during the team leader meetings.

Discussion during the walk tended to be very place specific, ant the team leaders pointed to the walls, joints and installations in question. They even painted marks straight on the walls to indicate where certain installations should be. All disciplines at the site were involved in discussions.

Issues form the team leader walk was brought back to the team-leader meeting the following Mondays, but not all that had been discussed during the walk was taken up. One of the team-leaders commented: 'The team-leader walk was useful; a lot of things were solved right there." Based on our observations of both walks and meetings, it seems that the majority of issues were solved at the walk directly, freeing up time in the meeting. In general, the kind of issues which tended to be solved was connected to coordination between the teams. The most common topics was:

- Details about storing materials and equipment: For example, the team leader for ventilation installers said that they would have a rather large pile of pipes coming in next Friday, and discussed with the carpenter and the electrician where to store it in order for it to be out of the way for their work, while still being accessible for his team.

- Details about location of pipes, electrical installations, timber frames and rails.

- Details regarding dimensions of walls, fittings and holes.

- Misunderstandings that had occurred during team leader meetings and other planning activities which were discovered during the walk.

The kinds of issues not being solved at the walks, tended to be related to decisions outside the jurisdiction of the team-leaders and the team-leader meeting. For example, mayor deviations from the model they saw the need for, but which involved decisions calling for management or architects. Also, issues regarding staffing is included in this category. During the walks, certain issues also came up which could not be solved in a satisfying way, even if it was brought to the team leader meeting and 'up in the system'. Such issues were for example delayed deliverances from component producers, groundwork blocking the way for just in time deliveries, or missing decisions from client. Many of these hindrances was detected during the team leader walk earlier than they would have been without the walk. As such, actions were taken earlier, but as they could not be solved in time, they also created frustration (and eventually contributed to the break-down of TAKT production). 


\section{DISCUSSION}

Observations of the team-leader walks indicate that it helped the team-leaders to see further ahead when planning and coordinating their work. The follow-up interviews confirmed this observation. However, the team leader from the carpenters found the walk to be more useful than the team-leaders from the technical professions. A reason for this difference may be that the technical team-leaders work for sub-contractors, while the carpenter teamleader represent the contracting entrepreneur, thus having the mayor responsibility for coordinating the work on the site. Also by the very nature of their work (building the walls and roofs holding the technical installations), the carpenters played a greater role in accommodating for the other disciplines. The carpenter team-leader also was the one who took reasonability for organising the walks.

While all team-leaders was positive regarding the effect of the walk, they also voiced concerns for the time-use caused by the walk. The technical team-leaders, were significantly more concerned than the team-leader from the carpenters. This difference can be explained by the different roles they had: The carpenter was dedicated to team-leading, spending all his time managing the team of carpenters. The technical team-leaders on the other hand also took active part in the production, as their teams only consisted of 3-5 professionals. Thus, less time could be dedicated to leader tasks.

Further, the experiments with the team-leader walk raised issues pointing to other aspects of the way the construction process was organised, in particular regarding the link between the team-leader level and the higher levels in the project. Enhancing the teamleaders ability to see and plan in more detail three weeks ahead, reviled the importance for the team-leaders to be able to discuss issues laying three weeks ahead with the higher levels. Here we saw a weakness in the production system which it wold be beneficial to address.

The need to discuss issues with management should be seen in connection with the Last Planner-like practice of Involved Planning. Involvement of builders did not only concern making the TAKT-plan. The involvement in planning also continued during the production. TAKT as a production system did not run like an autonomous machine. The 'machine' of TAKT needs continuous planning, adjustment and modification in order to be shielded from the irregularities of the outer world and run smoothly (Fyhn and Søraa 2017). This continuous planning calls for good routines allowing the levels of planners to work together. Here we see that the team leader walk can contribute, and the contribution may be enhanced by improving the communication between team-leader level and the higher levels (e.g. from team-leader meeting to operation meeting).

Considered as a communication tool, the team-leader walk, using the building itself as such tool, holds certain qualities other communication tools does not hold, qualities giving it potential to improve the construction process. The building is at any time the most updated version of the construction-process, thus ensuring the discussion and planning to be accurate and up to date. The building site also seems to appeal to an embodied understanding of time, space and tasks, as the team leaders actually walk through the actual space which represent their own status in 1-3 weeks. The physical nature of the building also seems to appeal to practical and embodied thinking over the more abstract thinking 
associated with representational engineering models. As such, it fits better into the cognitive expertise of many team-leaders, which are craftspeople, not engineers.

A possible down side of this communication tool is that one has to leave the meeting room (a room specially set up to enhance talking and planning) in order to use it. The actual building site tends to be a place filled with noise, dust and danger. Also, it is less ideal for combining with drawings and BIM, even though these tools are possible to use at the site. One reason why these tools was not used so much may be because the carpenters tended to rely on drawing, while the technical team leaders tended to rely on BIM directly.

Understood as communication tool, the team-leader walk should be considered in relation to BIM, drawings and other communication tools in use. A hypothesis for further studies is that a more systematic use of these tools, in particular BIM on a pad, could make the walk even more productive.

\section{CONCLUSION}

Experiences with the team-leader walk from two case studies indicate that it is a useful supplement to the team-leader meeting in TAKT and space-based construction processes. By appealing to the practical expertise of team-leaders, and giving the planned progression in time a spatial expression, it helps the team-leaders to better look ahead in their interdisciplinary planning and coordination of activities. The fact that the team-leaders decided to continue the walks, even without TAKT production indicates that the teamleader walk can be more robust than the TAKT production itself.

The walk is useful to give inputs to the team-leader meeting, and for sorting out coordination issues during the walk. A question for further research is how to integrate the team-leader walk in the established meeting structure enhancing the contribution of teamleaders in the planning. Another question worth pursuing is the combination of team leader walk and other communication tools.

\section{ACKNOWLEDGMENTS}

Many thanks to Marie Nilsen and the team leaders of Veidekke for great collaboration and help with the research. This paper is funded by the NRC project KSS.

\section{REFERENCES}

Alarcon, L.F. (Ed.). (1997). Lean Construction. A.A. Balkema, Rotterdam, The Netherlands.

Andersen, Lars (2016). Organisering av komplekse prosesser. Vitenskapsteoretiske og filosofiske foutsetninger. Fagbokforlaget.

Ballard, H. G. (2000). The Last Planner System of Production Control. Thesis for Doctor of Philosophy, Faculty of Engineering, The University of Birmingham.

Boland, J and Tenkasi, R.V. (1995): "Perspective Making and Perspective Taking in Communities of Knowing." Organization Science. Vol 6. No 4. 350-372 
Franson, a. Seppänen, Bergheide, K., and Tommelein, I. D. (2014). Takt-Time Planning and the Last Planner. $22^{\text {th }}$ Ann. Conf. of the International Group for Lean Construction (IGLC 22), Oslo, Norway June 25-27, pp. 571-580.

Fyhn, Håkon; Søraa, Roger Andre. (2017) Craftsmanship in the machine: sustainability through new roles in building craft at the technologized building site. Nordic Journal of Science and Technology Studies 2017 Vol. 5 (2) s. 71-84

Womack, Jim (2011). Gemba Walks. Lean Enterprise Institute, Inc. p. 348. 
Fyhn, Håkon and Andersen, Lars

1262

Proceedings IGLC - 27, July 2019, Dublin, Ireland 